\title{
Optimum Multiparameter Analysis of the Water Mass Structure in the Western North Atlantic Ocean
}

\author{
HANS-HARALD HINRICHSEN
}

Institut für Meereskunde an der Universität Kiel, Kiel, Germany

\author{
MATTHIAS TOMCZAK
}

Ocean Science Institute, University of Sydney, Sydney, New South Wales, Australia

\begin{abstract}
Hydrographic data of temperature, salinity, oxygen, nitrate, phosphate, and silicate at 81 stations with 435 samples on 3 sections between the Azores, the Grand Banks of Newfoundland, and the Bermuda Islands are used to determine the mixing of water masses by optimum multiparameter analysis over the depth range $100-1500 \mathrm{~m}$. The method optimally utilizes all information from our hydrographic data set by solving an overdetermined set of linear mixing equations for all parameters using the method of least squares residuals. It is shown that the method gives quantitative information on the influence of the various water masses of the western North Atlantic. The Gulf Stream and the North Atlantic Current appear as broad bands transporting large amounts of Western North Atlantic Central Water at their warm flank. Western Subarctic Intermediate Water and Shelf Water supplied by the Labrador Current and containing significant amounts of Labrador Current Water are found on their inshore side. The area of the Azores front is found in the vicinity of the Corner Seamounts, where the uniform water mass distribution of the Sargasso Sea changes into a more complex structure that reflects the influence of water masses originating in the Labrador Sea. Small-scale structures, like eddies or Gulf Stream rings, are also detectable by this analysis method. Comparison with dynamic height analysis supports the circulation pattern of the North Atlantic Current as a continuation of the Gulf Stream, and of the southeastward flowing Azores Current originating in the area of the Southeast Newfoundland Rise.
\end{abstract}

\section{INTRODUCTION}

The branching region of the Gulf Stream southwest of the Grand Banks has been studied by several authors during the past. Clarke et al. [1980] investigated the area between $36^{\circ} \mathrm{N}$ and Flenish Cap. Their results show the North Atlantic Current (NAC) as a continuation of the Gulf Stream, carrying large amounts of warm water to the north, and a southern branch, called the Azores Current (AC), which flows eastward [Gould, 1985; Käse and Siedler, 1982; Käse et al., 1985]. Results from near-surface studies based on hydrographic data, satellite-tracked buoys, and infrared images support this circulation pattern [Krauss et al., 1990].

The discussion of the distribution and mixing of water masses presented here is based on hydrographic and nutrient data obtained along three sections between the Azores, the southern tip of the Grand Banks of Newfoundland, and the Bermuda Islands in the depth range $100-1500 \mathrm{~m}$. The data set was discussed in detail by Krauss et al. [1990], who analyzed the eddy field and the branching of the Gulf Stream into the $\mathrm{NAC}$ and the AC.

The complex circulation of the area, which is strongly influenced by Gulf Stream meanders and rings, is reflected in high variability of the temperature, salinity, oxygen, and nutrient fields. Hydrographic parameters have often been used as indicators for determining the spreading of water

\footnotetext{
${ }^{1}$ Now at Flinders Institute for Atmospheric and Marine Sciences,
} Flinders University, Adelaide, South Australia.

Copyright 1993 by the American Geophysical Union. masses and quantitative inventory of water masses. Water mass properties of this area were discussed by Wright and Worthington [1970], Worthington. [1976], and Clarke et al. [1980], among others. Metcalf [1969] and Mann et al. [1973] give a description of the silica distribution.

The main feature below the surface layer is the Western North Atlantic Central Water (WNACW) transported by the Gulf Stream and the NAC. Multiparameter analysis represents all water masses by linear combinations of water types. Points in parameter space which belong to one of these linear combinations are referred to as source water types [Tomczak and Large, 1989]. The temperature-salinity (TS) properties of WNACW are specified completely by only two water types, namely, the end points $\mathrm{P} 1=\left(7^{\circ} \mathrm{C}, 35.0\right)$ and $\mathrm{P} 2=\left(18^{\circ} \mathrm{C}, 36.6\right)$ [Emery and Meincke, 1986] of its linear TS relationship. All its other source waters can be considered as linear combinations of these. It is worth stressing that this does not imply a particular mixing or formation process; WNACW is not formed by vertical mixing between P1 and P2 but by subduction from the surface along isopycnals. It does, however, offer an opportunity to represent WNACW as a linear combination of $\mathrm{P} 1$ and $\mathrm{P} 2$ in quantitative mixing analysis.

The depth range of WNACW extends to $1000 \mathrm{~m}$ at mid-latitudes and decreases toward higher latitudes. Dissolved oxygen varies from $5.5 \mathrm{~mL} / \mathrm{L}$ at the upper end of the range $(\mathrm{P} 2)$ to a minimum of $3.5 \mathrm{~mL} / \mathrm{L}$ at the lower end $(\mathrm{P} 1)$, while silicate increases from $2.5 \mu \mathrm{mol} / \mathrm{L}$ at the surface to about $15 \mu \mathrm{mol} / \mathrm{L}$ near $800 \mathrm{~m}$. Below WNACW, Antarctic Intermediate Water (AAIW) originating from the Polar front of the southern hemisphere can be traced as far as $40^{\circ} \mathrm{N}$ by its low oxygen $(3.5 \mathrm{~mL} / \mathrm{L})$ and high silica content $(22$ $\mu \mathrm{mol} / \mathrm{L})$ centered at about $1000-\mathrm{m}$ depth. 
The major water mass in the depth range between $1000 \mathrm{~m}$ and $1500 \mathrm{~m}$ is the Labrador Sea Water, hereinafter referred to as the upper North Atlantic Deep Water (NADW). Intermediate Water of Arctic origin, referred to as Western Atlantic Subarctic Intermediate Water (WASIW), is also seen in the data on occasion. Both water masses are formed by convection due to surface cooling and are therefore characterized by high oxygen $(>6 \mathrm{~mL} / \mathrm{L})$ and low silicate values $(<15 \mu \mathrm{mol} / \mathrm{L})$. They sink rapidly to depths between $1000 \mathrm{~m}$ and $3000 \mathrm{~m}$ and enter the area from the north and east. In depths around $1000 \mathrm{~m}$, Mediterranean Water (MW) of high salinity and low silicate penetrates the area from the east, in coincidence with the classical feature seen in the Meteor atlas [Wüst and Defant, 1936], which shows a westward protruding tongue with core layer anomalies of more than $30 \% \mathrm{MW}$ reaching as far as $50^{\circ} \mathrm{W}$.

The presence of the southward flowing Slope Water Current [McLellan, 1957] and the Labrador Current (LC) further north leads to a very complex hydrographic situation in the western part of the North Atlantic Ocean and new mixtures of the aforementioned water masses. Five such mixtures can be identified in the study area. In the depth range $0-1000 \mathrm{~m}$, the major components at the lower end are WNACW and Labrador Current Water (LCW) characterized by temperatures below $4^{\circ} \mathrm{C}$ and salinities in the range 34.2-34.95. Mixing of LCW and WNACW at the slope produces a new water mass which sinks to $2000 \mathrm{~m}$ and below as a result of caballing [Krauss et al., 1990]. Slope Water (SW), originating in coastal regions and characterized by cold and fresh water saturated with oxygen, is found at the shallow stations. Finally, mixing of SW with WNACW produces the characteristics of the water described by Soule [1951], who refer to it as "Mixed Water."

The large variety of water masses and mixtures places severe restrictions on quantitative water mass analysis. Derivations and conclusions from TS diagrams do not go beyond qualitative descriptions of the hydrographic situation. The present study is an attempt to extract quantitative information on the ranges of influence for the various water masses by combining TS data with observations of oxygen and nutrients.

\section{Data and Methods}

The data were obtained by R/V Poseidon in 1987 and described by Krauss et al. [1990]. The area of observation was surveyed by three hydrographic sections spanning a triangle Azores-Newfoundland-Bermuda-Azores (Figure 1). The instrument used was a Neil Brown conductivitytemperature-depth profiler (CTD) mounted inside a General Oceanics rosette sampler with a capacity of 12 Niskin bottles. For the purpose of this study, observations of oxygen, nitrate, phosphate, and silicate content obtained from 12 Niskin bottles in the rosette sampler were combined with in situ temperature and salinity data obtained from the CTD when the bottles closed. A total of 81 stations are available, distributed along three sections. Temperature, salinity, and oxygen observations were available for each of the stations, but the horizontal resolution of nutrient data varied from 40 to $80 \mathrm{n}$. $\mathrm{mi}(1 \mathrm{n} . \mathrm{mi}=1.852 \mathrm{~km})$ on the section from Bermuda to the Azores.

Analysis of the data is based on the method of optimum multiparameter (OMP) analysis described by Tomczak and

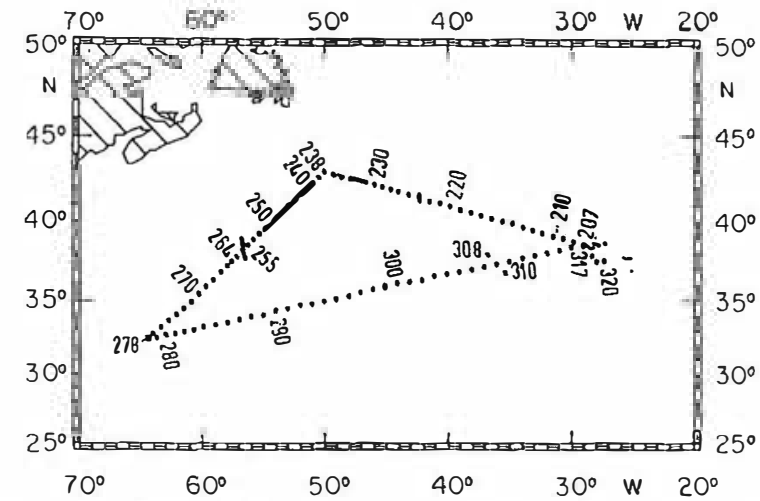

Fig. 1. Poseidon 138 cruise track, March/April 1987, showing CTD stations.

Large [1989]. The method requires representation of all water masses through water types and solves the linear system of mixing equations for all available parameters by minimizing the residuals. Weights are allocated to the various parameters according to environmental variability and instrumental precision; for each parameter $i$, the corresponding weight $w(i)$ is determined as $w(i)=\operatorname{var}(i) w t /$ $\operatorname{var}(i) w m$, where $\operatorname{var}(i) w t$ is the variance, for parameter $i$, of the water types, and $\operatorname{var}(i) w m$ the largest variance found in the source regions of the water masses (for details, see Tomczak and Large [1989]). In the present application $\operatorname{var}(i) w m$ was taken to be the variance determined for the most frequently observed WNACW, since the data set's extension of other water masses into the formation regions is either relatively sparse or poorly satisfied.

With six observation parameters (and the mass conservation equation, which is included in the linear system of mixing equations), the OMP method can analyze mixtures of up to seven water types. The number of water masses resolved by the procedure depends on the number of water types needed to represent each water mass. In the present case, only WNACW requires representation through two water types; all other water masses can be described by one water type each. Given the number of water masses found in the study area, it is still not possible to apply OMP analysis to all water masses simultaneously. The results presented here were therefore obtained by selecting at each station only those water masses for analysis which could reasonably be expected to be present. The review of Emery and Meincke [1986], which shows the geographical distribution of several water masses, was used as a guide. Different combinations of water masses were tried for stations where this decision could not be easily made, and the oceanographically most meaningful solution selected. The selection of water masses and possible alternatives are documented with the results.

OMP analysis solves the linear system of mixing equations

$$
G x-d=R
$$

where $G$ is the matrix of source water types to describe the water masses, $x$ is the solution vector, $d$ is the vector containing the observations, and $R$ is a vector of residuals. The system of equations is solved individually for each data point (see Tomczak and Large [1989] for details), so the method does not require the simultaneous inversion of very 
TABLE 1. Water Type Definition and Parameter Weights

\begin{tabular}{|c|c|c|c|c|c|c|c|c|c|}
\hline Parameter & $\begin{array}{c}\text { Upper } \\
\text { WNACW }\end{array}$ & $\begin{array}{c}\text { Lower } \\
\text { WNACW }\end{array}$ & AAIW & WASIW & NADW & MW & LCW & $\mathrm{SH}$ & Weight \\
\hline Temperature, ${ }^{\circ} \mathrm{C}$ & 19.00 & 7.00 & 3.50 & 3.70 & 3.500 & 13.20 & -0.28 & 10.026 & 13.610 \\
\hline Salinity & 36.65 & 35.00 & 34.55 & 34.80 & 34.945 & 37.72 & 33.33 & 34.969 & 13.610 \\
\hline Oxygen, mL/L & 5.40 & 3.80 & 3.80 & 6.40 & 6.250 & 4.60 & 8.25 & 5.820 & 3.024 \\
\hline Nitrate, $\mu \mathrm{mol} / \mathrm{L}$ & 2.00 & 20.00 & 33.00 & 17.00 & 17.600 & 9.10 & 4.70 & 12.160 & 3.568 \\
\hline Phosphate, $\mu \mathrm{mol} / \mathrm{L}$ & 0.15 & 1.30 & 2.30 & 1.10 & 1.100 & 0.65 & 0.60 & 0.980 & 3.367 \\
\hline Silicate, $\mu \mathrm{mol} / \mathrm{L}$ & 2.00 & 15.00 & 45.00 & 10.00 & 11.000 & 6.50 & 4.30 & 6.580 & 6.379 \\
\hline
\end{tabular}

large matrices. It requires, however, knowledge of the matrix $G$ before analysis can proceed. Definition of temperature and salinity values does not usually pose a problem, but finding reliable oxygen and nutrient data for source water types can be more difficult. In this paper, source water types were derived from information in the literature and other cruises as follows: (1) the water mass definitions of Emery and Meincke [1986] were used for most temperature and salinity values, (2) Geochemical Ocean Sections Study (GEOSECS) data were taken for the definition of nutrient and dissolved oxygen values and for temperature and salinity values of AAIW [Bainbridge, 1976], (3) water masses originating at the continental shelf of North America and in the Labrador Sea were defined by means of station data from our own data set, and (4) the source water type for MW was determined from station data obtained during several expeditions of the Institut für Meereskunde into the outflow regime of the Gulf of Cadiz [Rhein and Hinrichsen, 1993].

Only data in the depth range of upper and intermediate waters $(0-1500 \mathrm{~m})$ will be considered in the analysis. Because of the relatively coarse vertical resolution of the rosette sampler, this gives six observation levels at every station. Samples were taken at depths of $100,400,600,800$, 1000 , and $1500 \mathrm{~m}$ along the sections from the Azores to the Newfoundland shelf and from Newfoundland to the Bermuda Islands. Observation depths changed to $100,400,600$, 900,1200 , and $1500 \mathrm{~m}$ along the section from the Bermuda Islands to the Azores. Deviations from these depths were of the order of a few meters throughout; therefore vertical representation of results from our analysis is based on nominal depths.

\section{RESULtS}

The results of our study are presented in two ways. The first part of the analysis shows averaged results for groups of stations along the three sections. This gives an overview over the large-scale distribution of water masses and identifies the major constituents of the different hydrographic regions within the observation area, allowing a first assessment of the mean circulation. The second part addresses the detailed structure of the water mass distribution by analyzing individual stations. The relative contribution, or fraction, of each water mass is presented in three sections through the Gulf Stream, the NAC, and the AC, to demonstrate the probable lateral and vertical changes that result from the mixing processes involved.

Because of the low vertical resolution of bottle casts, representation of results by means of contour plot along vertical sections depends to a large extent on the interpolation algorithm. Another difficulty is that most contouring routines find it difficult to contour data if plotted features are present at single stations only. For these reasons we decided to present our results in the form of pie charts and colorcoded box graphs, which are more appropriate to the density of our data set.

The definitions of water masses for the application of OMP analysis in the branching region of the Gulf Stream, including the computed weights for the observed parameters, are given in Table 1, and a schematic representation of the typical TS characteristics is shown in Figure 2.

\subsection{Large-Scale Distribution}

3.1.1. Azores-Newfoundland section. Plate $1 a$ shows the mean percentages of the water masses found between the Azores and Newfoundland (no solution could be obtained for the group of stations located at $40^{\circ} 39^{\prime} \mathrm{N}, 38^{\circ} 32^{\prime} \mathrm{W}$, for the 100 -m level owing to the lack of sufficient nutrient information). The upper waters east of $45^{\circ} \mathrm{W}$ were dominated by WNACW, which reached its maximum of $92.6 \%$ in the area of the warm flank of the NAC at $100-\mathrm{m}$ depth. It is worth noting that WNACW is defined through two source water types (Table 1) and the fractions of WNACW given in this and the following figures are specified as the sum of the amounts of the upper and lower source water types. Shelf Water (SH), a water mass originating at the continental shelf of America, and water formed in the Labrador Sea transported by the Labrador Current (Labrador Current Water) complete the structure. The largest contribution of LCW is found at depths of $100 \mathrm{~m}$, whereas the denser $\mathrm{SH}$ is more evident in the depth range between 400 and $600 \mathrm{~m}$. Central Water is present throughout the 100 to $600 \mathrm{~m}$ depth range, decreasing downward. Further down, the influence of LCW and $\mathrm{SH}$ becomes insignificant while the influence of WNACW grows, reaching its maximum in the main thermocline at 800-m depth.

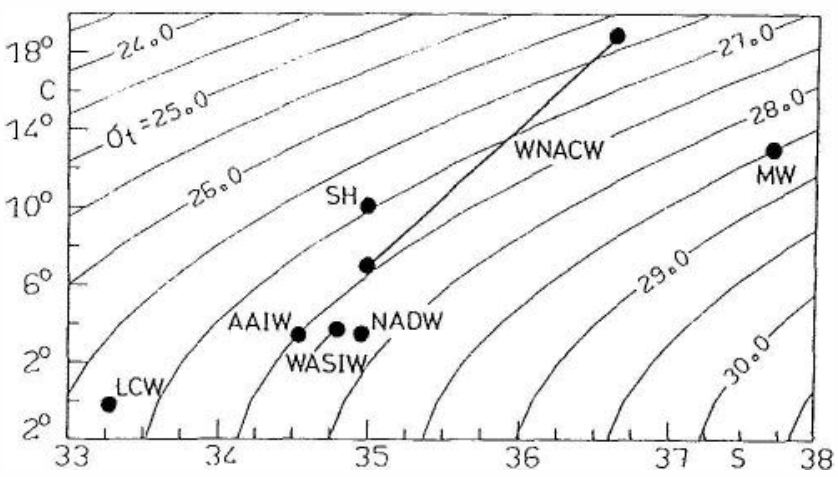

Fig. 2. Characteristic temperature-salinity (TS) relationships for the water masses in the upper layers and middepth of the Atlantic Ocean. 


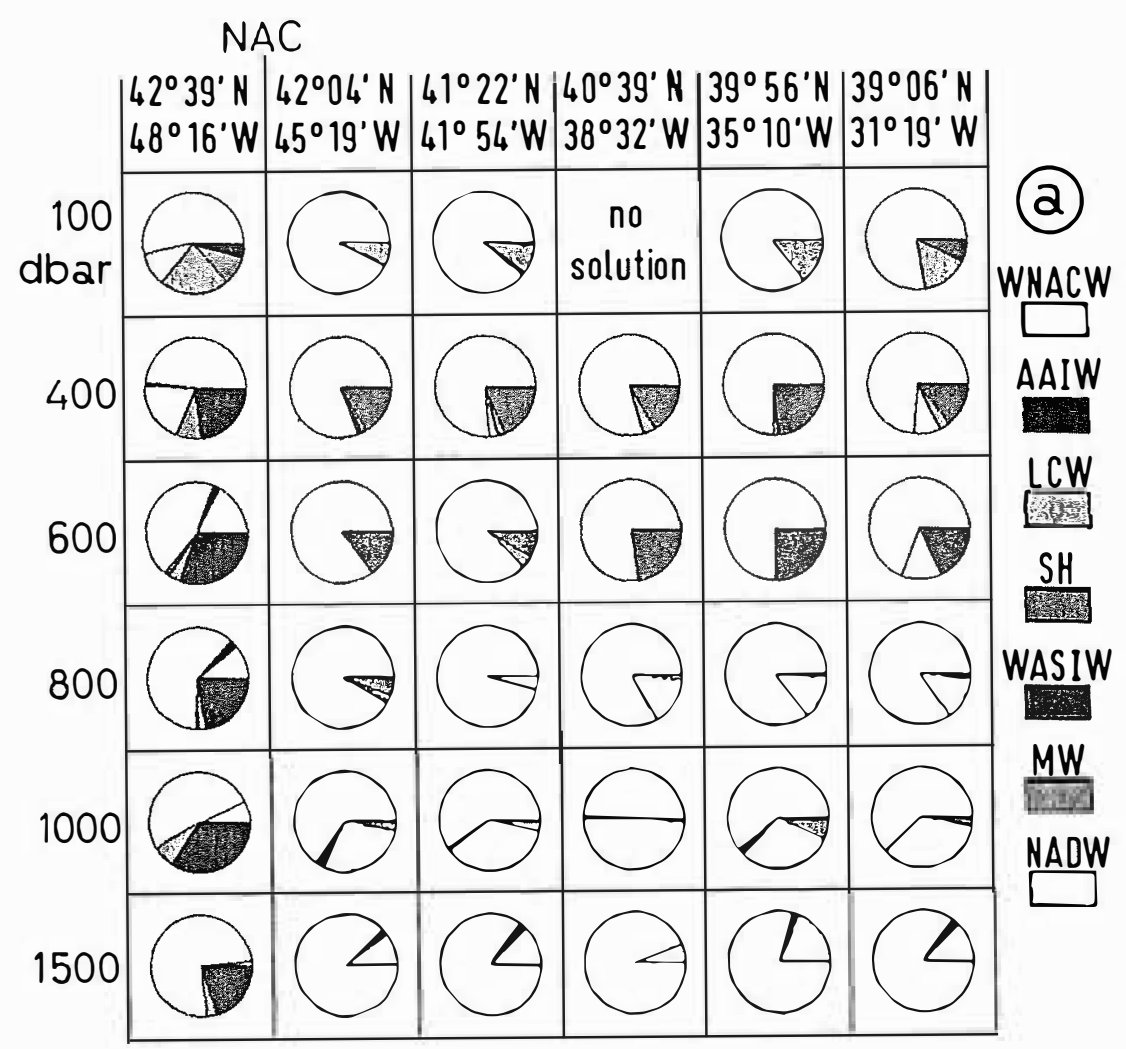

GULF STREAM

$33^{\circ} 15^{\prime} \mathrm{N}\left|35^{\circ} 12^{\prime} \mathrm{N}\right| 36^{\circ} 58^{\prime} \mathrm{N}\left|38^{\circ} 22^{\prime} \mathrm{N}\right| 39^{\circ} 40^{\circ} \mathrm{N}\left|40^{\circ} 37^{\prime} \mathrm{N}\right| 4^{\circ} 32^{\prime} \mathrm{N}\left|4^{\circ} 22^{\prime} \mathrm{N}\right|$ $60^{\circ} 17^{\prime} \mathrm{W} 60^{\circ} 35^{\prime} \mathrm{W} 58^{\circ} 18^{\prime} \mathrm{W} 56^{\circ} 28^{\prime} \mathrm{W} 54^{\circ} 4^{\prime} 4^{\prime} \mathrm{W} 53^{\circ} 24^{\prime} \mathrm{W} 52^{\circ} 08^{\prime} \mathrm{W} 50^{\circ} 55^{\prime} \mathrm{W}$

100

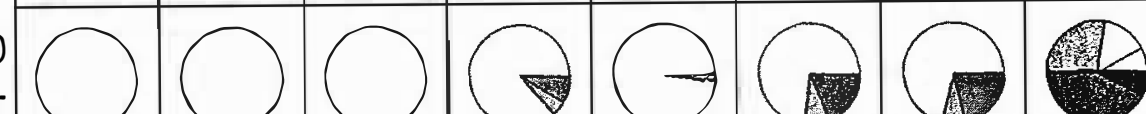

(b) dbar

400
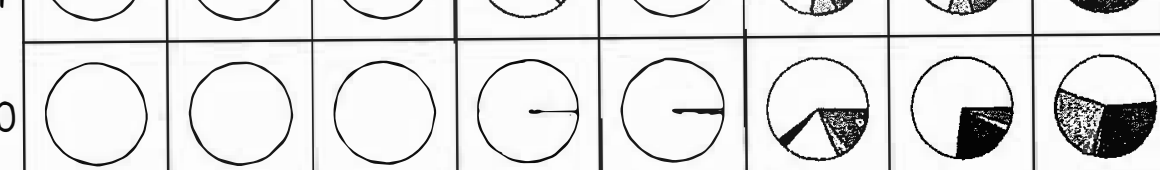

WNACW

600
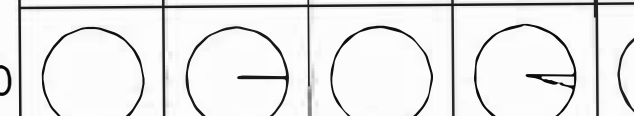

(1)
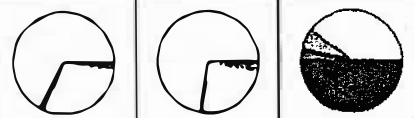

AAIW

AAIW

LCW

LCW

SH

800

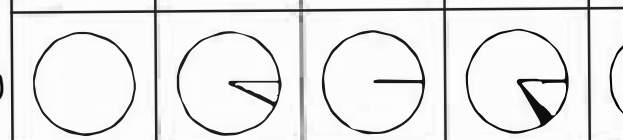

1000

1500

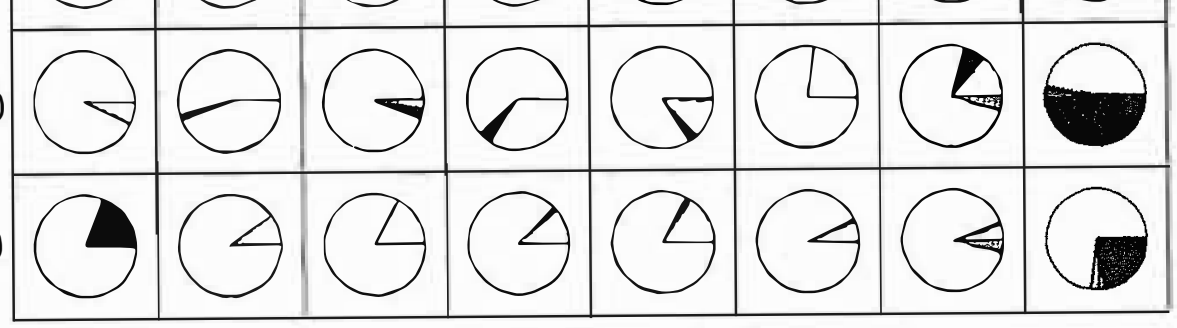

WASIW

MW

Mititi

NADW

Plate 1. Averaged water mass contribution, in percent, of hydrographic stations along the sections $(a)$ Newfoundland-Azores (NF-AZ), $(b)$ Bermuda-Newfoundland (BE-NF), and (c) Bermuda-Azores (BE-AZ). Positions represent the averaged locations of the group of stations. For better quality the contributions were added up to $100 \%$ as a result of normalization. 


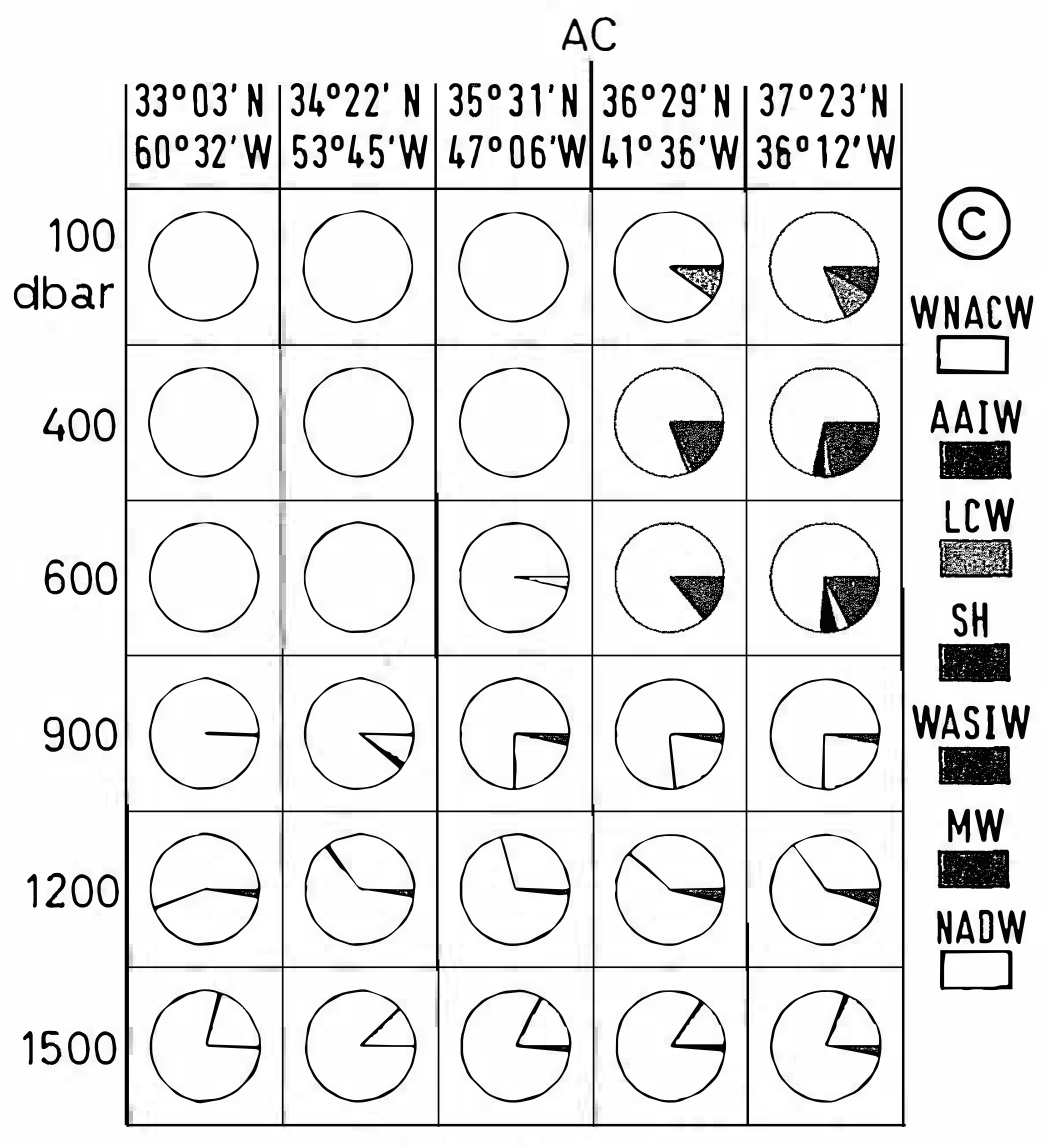

Plate 1. (continued)

The depth range $800-1500 \mathrm{~m}$ is characterized by the transition from central to deep water masses. The middepth waters east of $45^{\circ} \mathrm{W}$ consist mainly (up to $94 \%$ ) of NADW. Only small remainders of AAIW (about 2\%) occupy the intermediate part of the water column, whereas the upper deeper water of the North Atlantic is influenced by the spreading of warmer and saltier MW, released through the Strait of Gibraltar. The water mass distribution displays a small westward protruding tongue (1-7\%) reaching as far as $45^{\circ} \mathrm{W}$, in agreement with the classical picture of Wüst and Defant [1936].

The area west of $45^{\circ} \mathrm{W}$ exhibits quite different features. In the upper water the remaining part of WNACW decreases more rapidly with depth and is in close contact with the fresher Subarctic Intermediate Water (WASIW), believed to be formed in majority in the Labrador Sea. Only small fractions of $\mathrm{LCW}$ were found here, but in contrast to the region east of $45^{\circ} \mathrm{W}$ it is evident over the whole depth range from 100 to $1500 \mathrm{~m}$. Only very limited amounts of $\mathrm{SH}$ reach the western area, while propagation of MW is limited to the region east of the NAC. WASIW and NADW are the most dominant water masses, present in the whole analyzed depth range. The contribution of NADW varies from about $10 \%$ at $100 \mathrm{~m}$ to $75 \%$ at $1500 \mathrm{~m}$, the amounts at depths of 800 and $1000 \mathrm{~m}$ being significantly higher than at the same depths east of $45.30^{\circ} \mathrm{W}$. This can probably be explained by the closeness of the area to the formation area of NADW. The AAIW fraction in the west is as high as in the central and eastern part of the section.

3.1.2. Newfoundland-Bermuda section. The water mass structure at the northernmost part of this section is almost identical in character to that of the adjacent part of the Azores-Newfoundland section (Plate $1 b$ ). WASIW is among the most dominant contributors in the whole water column except at the $100-\mathrm{m}$ level, where the contribution from $\mathrm{SH}$ has its maximum. WNACW is evident only at this level, unlike the distribution in the counterpart to the east where it was observed down to depths of $1500 \mathrm{~m}$. Fractions of LCW, transported by the Labrador Current leaving the shelf region here, also occur in the same depth range. Furthermore, the contribution of NADW displays about the same high values for the upper waters.

Between $36^{\circ}$ and $42^{\circ} \mathrm{N}$ the results from OMP analysis for the $100-\mathrm{m}$ level correlate very well with sea surface temperatures determined by the Canadian Forces Meteorological Centre (Figure 3). The section cut through the Gulf Stream first in a large meander between $41^{\circ}$ and $42^{\circ} \mathrm{N}$, characterized here by deep penetration of WNACW and relatively strong intrusions of SH and LCW; WASIW has completely disappeared. The explanation for the relatively large amounts of LCW and SH is clearly found in the fact that the section only touched the Gulf Stream at its left flank, which has a large reservoir of cold and oxygen-rich waters supplied by the Labrador Current. Farther south $\left(40^{\circ} \mathrm{N}\right)$, the Gulf Stream was composed to depths of $600 \mathrm{~m}$ of almost pure WNACW. The area around $38^{\circ} \mathrm{N}$ features a cyclonic (cold core) ring south of the stream main axis, characterized by remnants of LCW and $\mathrm{SH}$ in the uppermost level and an increase of NADW toward smaller depths.

The results south of the cold core ring show a strongly 


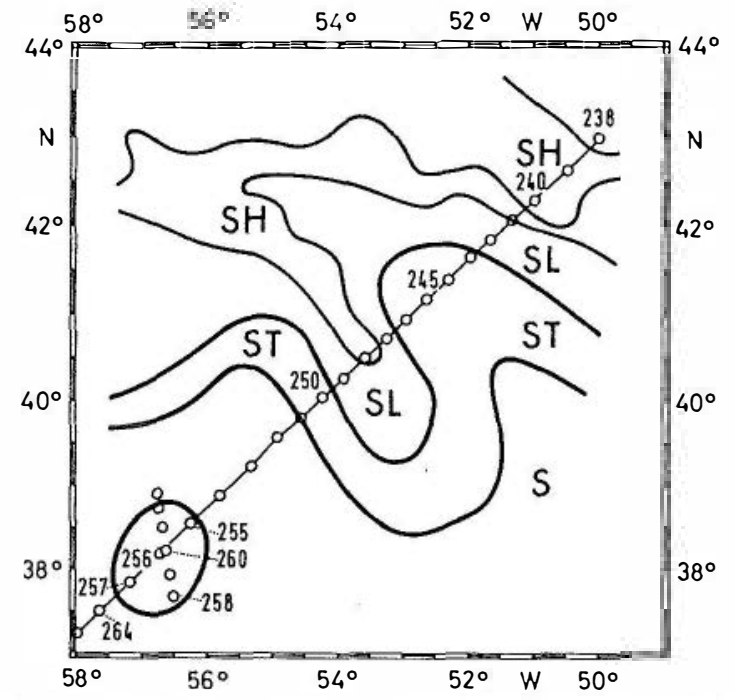

Fig. 3. Sea surface temperature on March 24, 1987, according to the Canadian Forces Meteorological Centre. Water masses according to this office are SH, Shelf Water; SL, Slope Water; ST, Gulf Stream; and S, Sargasso Sea.

different picture. LCW and SH are no longer present, and the section displays the structure typical of the Sargasso Sea, with only two main water masses (WNACW and NADW) present in the upper $1500 \mathrm{~m}$. The contribution of AAIW is only very minor (2-3\%). The amounts of AAIW increase toward smaller depths in the area north of the cold core ring, probably as a result of advection of separated "blobs" of this water mass.

3.1.3. Bermuda-Azores section. Plate $1 c$ shows the water mass distribution along the section through the recirculation region of the Gulf Stream in the Sargasso Sea in the west and the area of the Azores Current in the east. The Sargasso Sea contained mainly WNACW and NADW. The influence of the westward flowing MW is only very small here $(0.5-2 \%)$, and so is the influence of the AAIW, which contributes only $2 \%$ in its maximum. East of $42^{\circ} \mathrm{W}$, LCW and $\mathrm{SH}$ were evident again, confirming the description of Krauss et al. [1990], who found the crossing of the AC at the same location. The strongest contrast in the water mass distribution occurs in the depth range between 100 and 900 $\mathrm{m}$, again in good agreement with the results of Krauss et al. [1990], who observed the Azores Current as a continuous band, identified by dynamic topographies down to $1000-\mathrm{m}$ depth. The eastern part of this section has a more pronounced influence of the $\mathrm{MW}$; intrusions of $5 \%$ are found east of the $\mathrm{AC}$, a result rather different from those for the western part. The analysis yields unusually high amounts of AAIW in depths of 400 and $600 \mathrm{~m}$. AAIW, identified by the silicate maximum near $400 \mathrm{~m}$, could be traced into the Gulf Stream and as far north as the Newfoundland Banks. Mann et al. [1973] suggest that the silicate maximum in the Gulf Stream is a result of current advection. Our results point towards advection of individual "blobs" of AAIW particularly in the Bermuda-Newfoundland section. Observations of high AAIW content in the region to the west of the Azores might then indicate remnants of such Gulf Stream blobs, with lower silicate maxima due to mixing with WNACW. Therefore the observed values seem too high for this region, and as we cannot offer a physical explanation, we will exclude these stations from further discussion.

\subsection{Detailed Structure of the Water Mass Distribution}

For further interpretation of the results of our water mass analysis data, one has to refer to the representations of the hydrographic data (highly resolved temperature, salinity, and density fields) published in detail by Krauss et al. [1990].

3.2.1. Azores-Newfoundland section. This section (Plate $2 a$ ) illustrates very well the water mass structure of the area of the NAC, the westwind drift, and the northern part of the subtropical gyre in the eastern part near the Azores. The NAC is located between stations 229 and 237; it can be identified in the east by the warm saline pool of WNACW at the offshore flank of the current (stations 229-233). Further east (stations 226-229) a countercurrent transporting in mostly colder and less saline water masses appears. Closer to the shelf break region it carries colder, fresher water associated with well-ventilated water masses originating from the Labrador Sea. The two flanks can be separated by their WNACW fractions. The warm flank represents large amounts $(>75 \%)$ reaching as deep as 1000 $\mathrm{m}$, a result of advection in the Gulf Stream. The area west of the warm flank of the NAC looks quite different. A large WNACW fraction near the surface and a fraction amounting to more than $80 \%$ in the depth range to $400 \mathrm{~m}$ suggest that this water mass could be formed in the vicinity. A large percentage of any water mass does not necessarily reveal the location of formation, because water masses may have been formed elsewhere and advected to any other location without being altered. However, the global water mass summary of Emery and Meincke [1986] puts the formation region of WNACW in the vicinity of the Grand Banks, close to our observation region.

LCW and SH dominate the upper layers farther west and the depth range just below the region of likely WNACW formation; LCW and $\mathrm{SH}$ fractions are $>50 \%$ (station 237) and $>25 \%$ (station 236 ) in the upper layers $(100-400 \mathrm{~m})$ and unusually high at the 1000 -m level at station 235 (26\% LCW). This agrees well with results of a simple mixing model used by Krauss et al. [1990] which shows horizontal mixing of WNACW and LCW in a frontal region producing denser water through caballing. The resulting mixture sinks down as deep as $2000 \mathrm{~m}$, resulting in an additional geostrophic mass transport.

Another characteristic of this region is the prominence of WASIW with maximum fractions $>80 \%$ close to the shelf and lesser but significant amounts at station 233. The latter also is obvious in anomalously high oxygen and silicate contents at depths between 600 and $1000 \mathrm{~m}$. In the highresolution CTD data the presence of WASIW is seen as a tonguelike shape between the 100 - and $400-\mathrm{m}$ levels oriented from west to east. This feature is not resolved by the low vertical data density of the present oxygen and nutrient data set. The countercurrent observed by Krauss et al. [1990] to the east of the warm flank of the NAC is indicated by a minimum of the WNACW fraction near $1000 \mathrm{~m}$ at station 226 and a corresponding maximum of the NADW fraction. To the east of station 226 the hydrography is dominated by eddies of mesoscale type diameter. The major contributors to eddy waters in the main thermocline are WNACW (30$100 \%)$, SH (0-45\%) and LCW (0-18\%). A cold eddy near station 211 has an anomalously large SH fraction (45\%) at 600-m depth, comparable to a similar feature observed at the 
$\stackrel{N F}{233}-\mathrm{NAC}$

$237 \quad 235 ! 231:$
223

$226 !$
STAT. NO.
$\begin{array}{r:r}A Z \\ 209 \\ 210 & 207\end{array}$

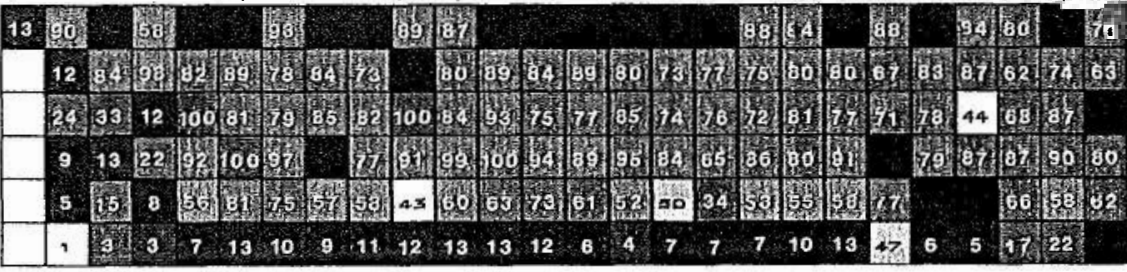
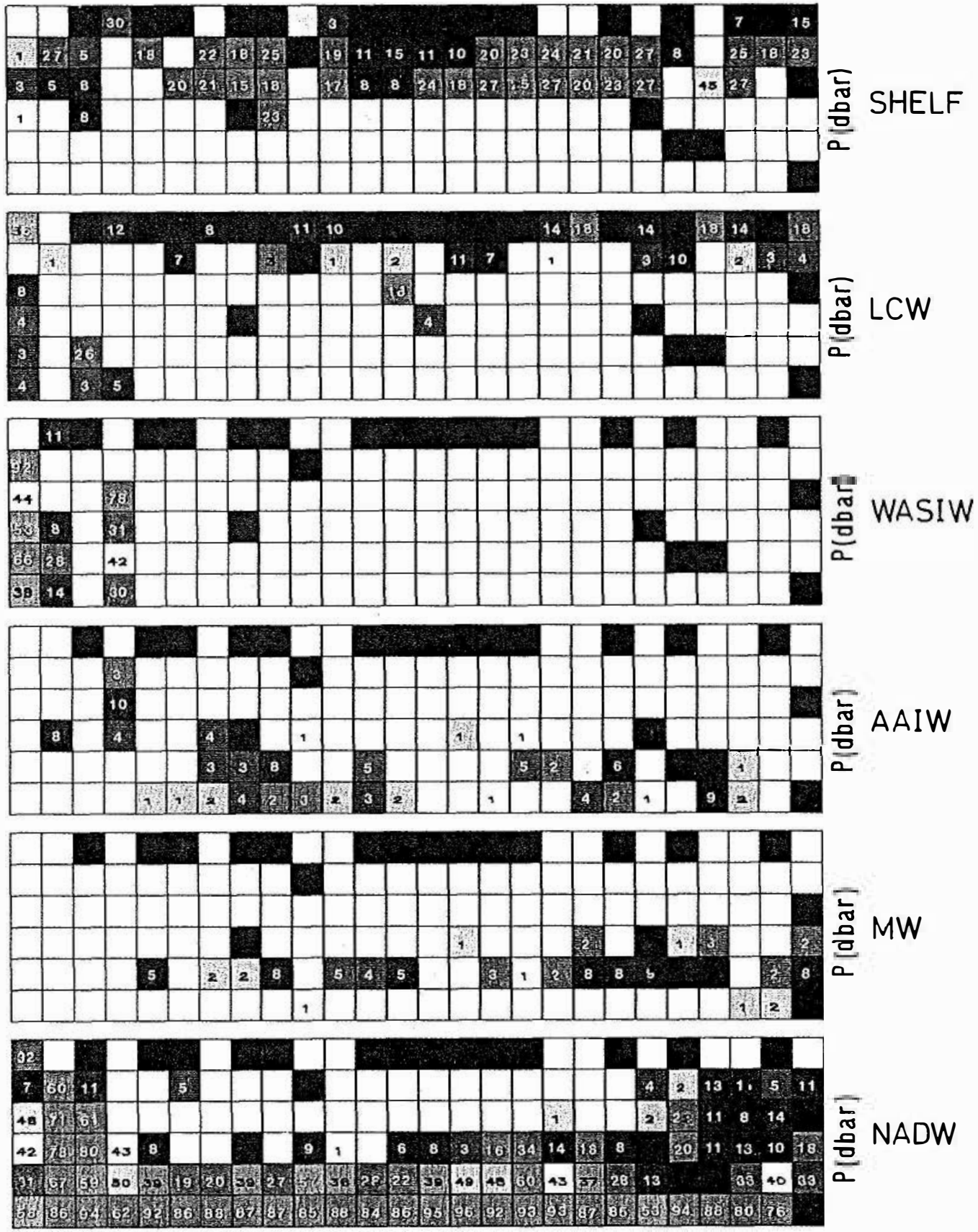

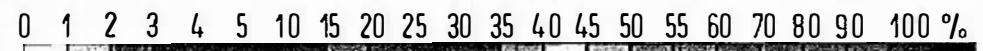

[

Plate 2. Water mass contribution, in percent, of hydrographic stations along the sections (a) Newfoundland-Azores (NF-AZ), ( $b$ ) Bermuda-Newfoundland (BE-NF), and (c) Bermuda-Azores (BE-AZ). Black boxes indicate no solution, due to the lack of nutrient information; blank boxes indicate water mass fractions of exactly zero. 

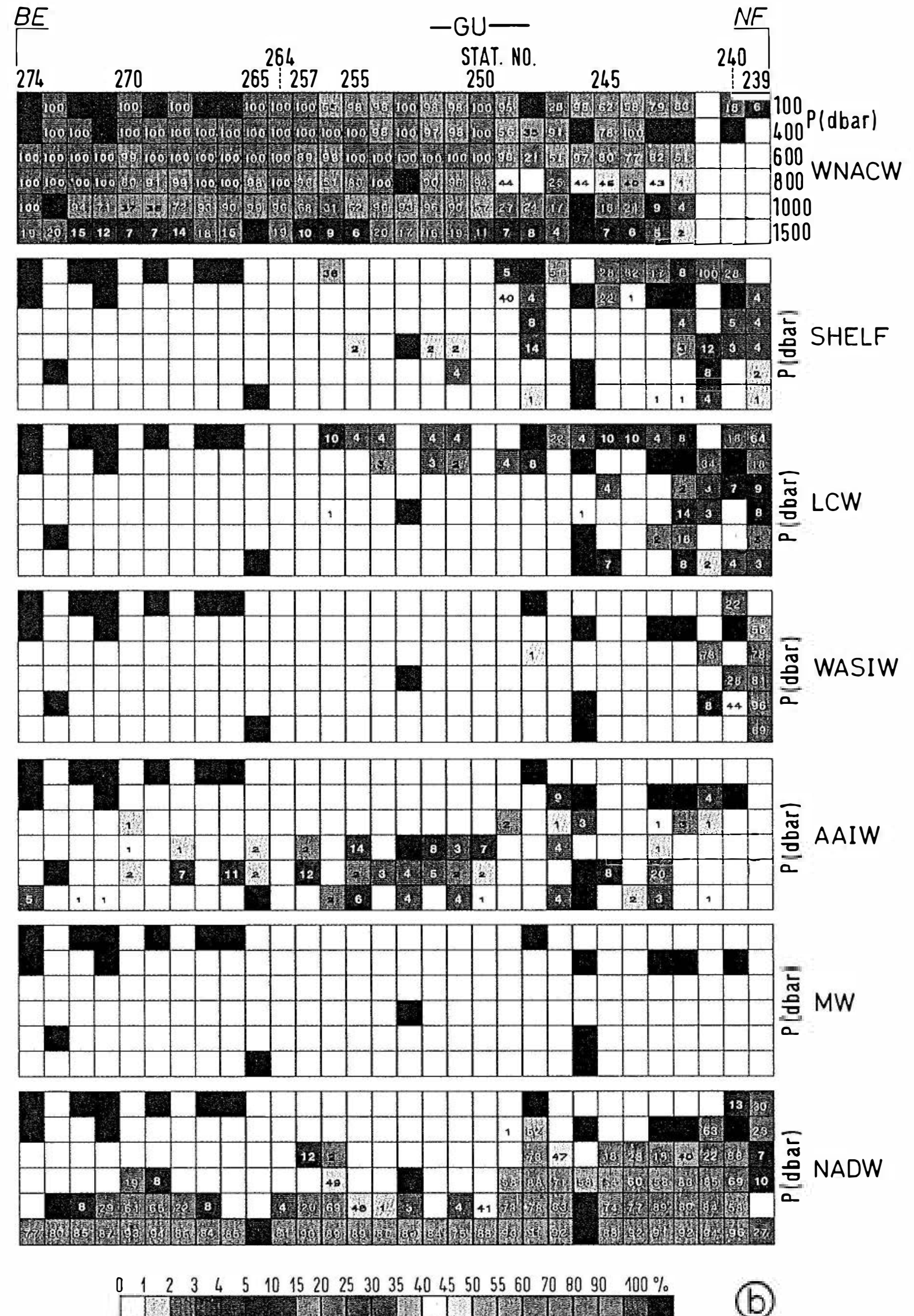

(b)

Plate 2. (continued) 


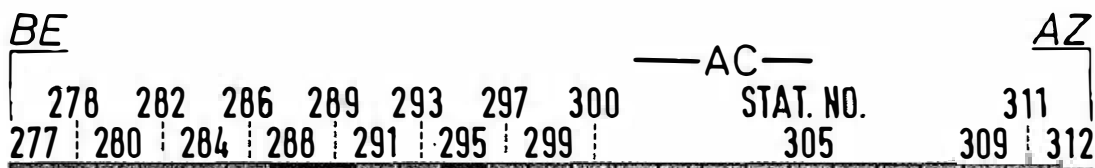

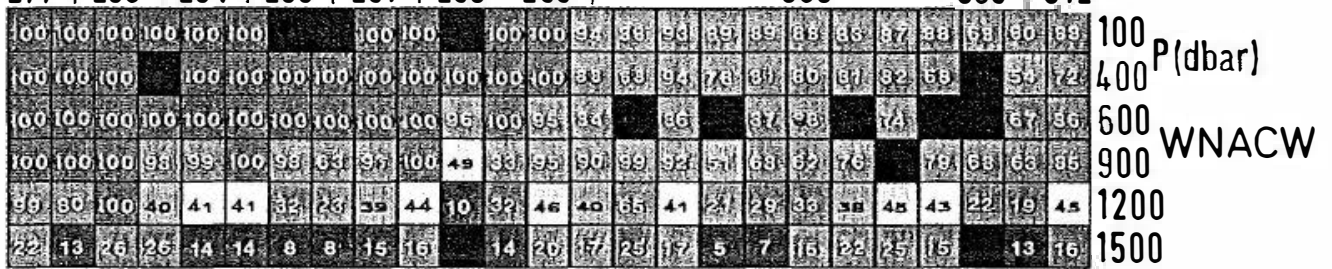
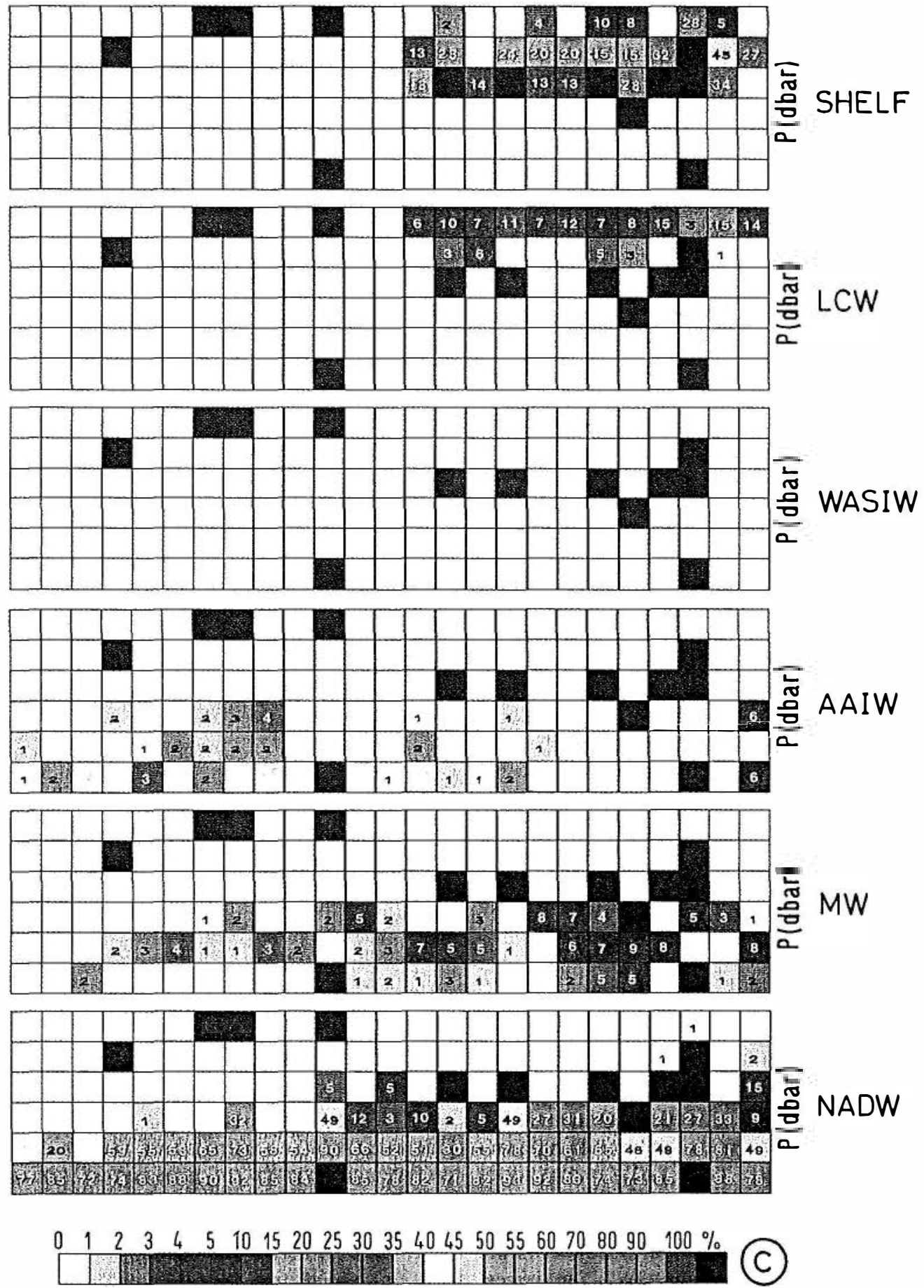

Plate 2. (continued) 
nearest geographical location on the Bermuda-Azores section (see below).

The water mass structure at middepth is weakly influenced by intrusions of MW and AAIW. MW was found in the depth range $800-1500 \mathrm{~m}$, with a maximum fraction of $9 \%$ at the $1000-m$ level and its westernmost extent into the warm flank of the NAC $(5 \%)$. Our analysis does not display a tonguelike spreading of MW but indicates a distribution more random in space and time. AAIW has its maximum values $(10 \%)$ in the area of the NAC in the west at a depth of $600 \mathrm{~m}$. Relatively large fractions $(8 \%)$ are also seen in the region of the countercurrent east of the warm flank of the NAC, and at station 211 (9\%), where the aforementioned strong cold eddy appears.

3.2.2. Newfoundland-Bermuda section. Water mass fractions along the section from Newfoundland to Bermuda are displayed in Plate $2 b$. Maximum amounts of WNACW $(100 \%)$ in the range of the main thermocline occur south of station 257, reflecting the more subtropical conditions of the Sargasso Sea. To the north, water masses are significantly colder and fresher as a result of relatively large LCW and $\mathrm{SH}$ fractions $(>5 \%$ and $>30 \%$, respectively). The region between stations 257 and 255 was occupied by a cold core ring (approximately $5^{\circ} \mathrm{C}$ colder and 1 psu less saline at the $100-\mathrm{m}$ level compared with the surrounding contributions) of elliptic shape centered near station 256 (Figure 3). This ring was covered by only eight stations during the hydrographic survey, and although additional temperature and salinity data are available, a detailed study of its mixing regime is impossible for lack of detailed nutrient information. Another cold core ring appears near station 270 marked by an increased NADW fraction at and below the $800-\mathrm{m}$ level. In contrast to the situation with the ring centered near station 256, this ring contained no LCW and SH fractions; the depth range $100-400 \mathrm{~m}$ was completely filled by WNACW.

Cold core rings are generally formed by south-extending meanders of the Gulf Stream east of the American continent off Cape Hatteras [Fuglister, 1971]. They have a cold core of Slope Water from north of the Gulf Stream and they can drift for more than a year in the Sargasso Sea [Ring Group, 1981]. Cheney and Richardson [1976] described the decay mechanism of rings as mixing with Sargasso Sea water. Comparisons of the water mass distribution of both cold core rings obtained by our analysis exhibits the southern one (station 270) as more vigorously influenced by advected Sargasso Sea water. This indicates that compared with the ring near station 256 , this ring is in an advanced stage of decay and thus probably older.

Generally speaking, the WNACW and NADW fractions complement each other south of station 250, apart from a weak AAIW influence near the 1000-m level; they are the only water mass fractions present in the Sargasso Sea. The spreading of AAIW is well defined in maps of the silicate distribution (not shown), which highlight the contrast between water masses of the northern and southern hemispheres [Kawase and Sarmiento, 1985]. AAIW moves northward through the present section in the western basin, so the intermediate layers are characterized by elevated silicate concentration. It is mainly this additional tracer signature that allows OMP analysis to trace AAIW. The largest observed fractions occur at the northern edge of the large Gulf Stream meander at station $243(20 \%)$ and in the area of the cold core ring around station 256 (14\%).
Sea surface temperature maps obtained from the Canadian Forces Meteorological Centre (Figure 3) indicate that this section cuts the Gulf Stream twice across a large meander between $40^{\circ}$ and $42^{\circ} \mathrm{N}$. The main axis of the Gulf Stream, typically marked by a sharp contrast between warm, saline water of subtropical origin and cold, fresh water masses advected from the north by the Labrador Current, showed geostrophic maximum velocities of $1.18 \mathrm{~m} / \mathrm{s}$ and was located in the area around station 250 . It is seen here as a maximum in the WNACW fraction (100\%) and a significant decrease toward north. Next to this "outcrop" region was an area of large intrusions, near stations 247-249, of SH (>50\%) and LCW (>20\%) corresponding to westward flow. The reduction of the WNACW fraction is combined with a sharp increase of NADW reaching more than $50 \%$ at the $400-\mathrm{m}$ level. The region between station 244 and 246 again reflects parts of the eastward flowing warm flank of the Gulf Stream correlated with a weak increase of WNACW and a decrease of $\mathrm{SH}, \mathrm{LCW}$, and NADW. As the continental slope is approached north of station 242, the water mass distribution shows again great complexity. The eastward flowing current contains large amounts of SH and LCW in the main thermocline. Significant LCW fractions (16\%) are found down to the $1000-\mathrm{m}$ level, a situation quite different from that found for adjacent stations in the south.

The water masses near the shelf represent one part of the recirculation of the Labrador Current. In the vicinity of the Grand Banks, part of the Labrador Current turns offshore, continuing northward inshore of the North Atlantic Current [Krauss et al., 1990]. The water mass distribution shows significant high amounts of SH and LCW in the upper layers. Another part stays close to the shelf; it is characterized by the filament of NADW and WASIW fractions reaching up to $96 \%$. The near surfacing of the NADW fraction and the dominance of WASIW near station 239 could indicate the vicinity of the formation region of both water masses.

3.2.3. Bermuda-Azores section. Plate $2 c$ represents the water mass distribution of the section that closes the triangle Azores-Newfoundland-Bermuda-Azores. The most conspicuous horizontal changes in that section are those in the main thermocline. In the west the water column down to $900 \mathrm{~m}$ is filled almost entirely by WNACW, with the region of pure (100\%) WNACW becoming shallower toward the east. These stations reflect conditions in the Sargasso Sea, which in the range $0-500 \mathrm{~m}$ are dominated by the $18^{\circ} \mathrm{C}$ water. The water mass composition changes east of the Corner Seamounts (station 300), with the fraction of WNACW falling off to $<90 \%$ at $100 \mathrm{~m}$ and significantly less below. This is accompanied by an increase of LCW and SH fractions in the main thermocline to $>10 \%$ and $>30 \%$, respectively. Both water masses are denser than WNACW, and the shift in water mass composition leads to a strong inclination of isopycnals between stations 301 and 303. The transition from pure WNACW to water with three or more constituents coincides with an increase of the southeastward flowing geostrophic current to geostrophic maximum velocities $>0.40 \mathrm{~m} / \mathrm{s}$ between stations 302 and 303 , the area of the Azores front and the Azores Current [Krauss et al., 1990]. To the north of the Azores front (the eastern end of the section), the section cuts again through a region dominated by the NAC and its eddies. The most prominent eddy feature occurs around station 311, where anomously cold and fresh water was observed, clearly visible by the increase of the 
LCW fraction (15\%) and particularly the SH fraction (45\%) in deeper layers.

Krauss et al. [1990] discussed the current field west of the Azores in detail and showed that the entire region was dominated by eddies. Generally, eddy velocities decreased from west to east. Cyclonic (cold) eddies were observed between stations 288 and 291 and between stations 295 and 297, while stations adjacent to Bermuda exhibited an anticyclonic (warm) eddy. The imprint of the eddy field on the water mass distribution is seen in the variation of the WNACW and NADW fractions. Cyclonic features correspond to smaller amounts of WNACW below a depth of 600-900 m and higher values of NADW in the intermediate depth range. The opposite is observed in anticyclonic eddies.

The dominant water mass below the main thermocline is NADW. In the Sargasso Sea the relation between the fractions of WNACW and NADW complement each other, whereas in the eastern part the upper deep water is strongly influenced by MW. The warm, saline MW makes a significant contribution to the area east of the Azores front with fractions up to $9 \%$ (station 307). Stations with such high MW fractions were characterized by strong perturbations in the temperature and salinity structure found from the CTD data, due to intrusions of MW and subsequent mixing. West of the Azores Front our analysis shows the westward spreading of the MW tongue with fractions below $5 \%$.

\section{Horizontal Water Mass Distribut? AND DYNAMIC TOPOGRAPHY}

Figure 4 shows both the large-scale virculation pattern in the western North Atlantic (dynamic height derived irom a combination of the hydrographic data set of 1986 and 1987 [Krauss et al., 1990]) and the large-scale water mass distribution for the 100- and 1000-m levels. Unfortunately, the 1986 data do not include any oxygen or nutrient measurements, so OMP analysis cannot be applied within the triangle of sections. Therefore one might expect that the alignment of water mass contours and dynamic topography may be highly fortuitous here, but error estimates of the objective analysis method reveal error variances of the estimated fields on average not larger than $25 \%$, except in the middle of the triangle $\left(39^{\circ} \mathrm{N}, 48^{\circ} \mathrm{W}\right)$, where values exceed $75 \%$. The good agreement in comparison of both parameters should from our point of view be regarded as more schematic in water mass distribution, although showing, for example, exactly the separation between the Sargasso Sea and the Azores Current regime (see below). Both patterns are estimated with a correlation scale of $500 \mathrm{~km}$ zonally and $300 \mathrm{~km}$ meridionally. The latter was chosen, because the large-scale property distribution in the Gulf Stream branching region exhibits a more pronounced zonal correlation. The configuration of the sections allows relatively good representation of the vertical distribution but cannot resolve details of the horizontal patterns of the water mass structure. Our horizontal maps therefore eliminate the eddy field; with the chosen correlation scale they give an overview over the large-scale situation.

The southwestern area may be seen as part of the northern Sargasso Sea and the Gulf Stream, as is well documented by high amounts $(>75 \%)$ of WNACW at the $100-\mathrm{m}$ level. Su,th of approximately $35^{\circ} \mathrm{N}$ this level was entirely covered by WNACW. The broad Gulf Stream enters the observation

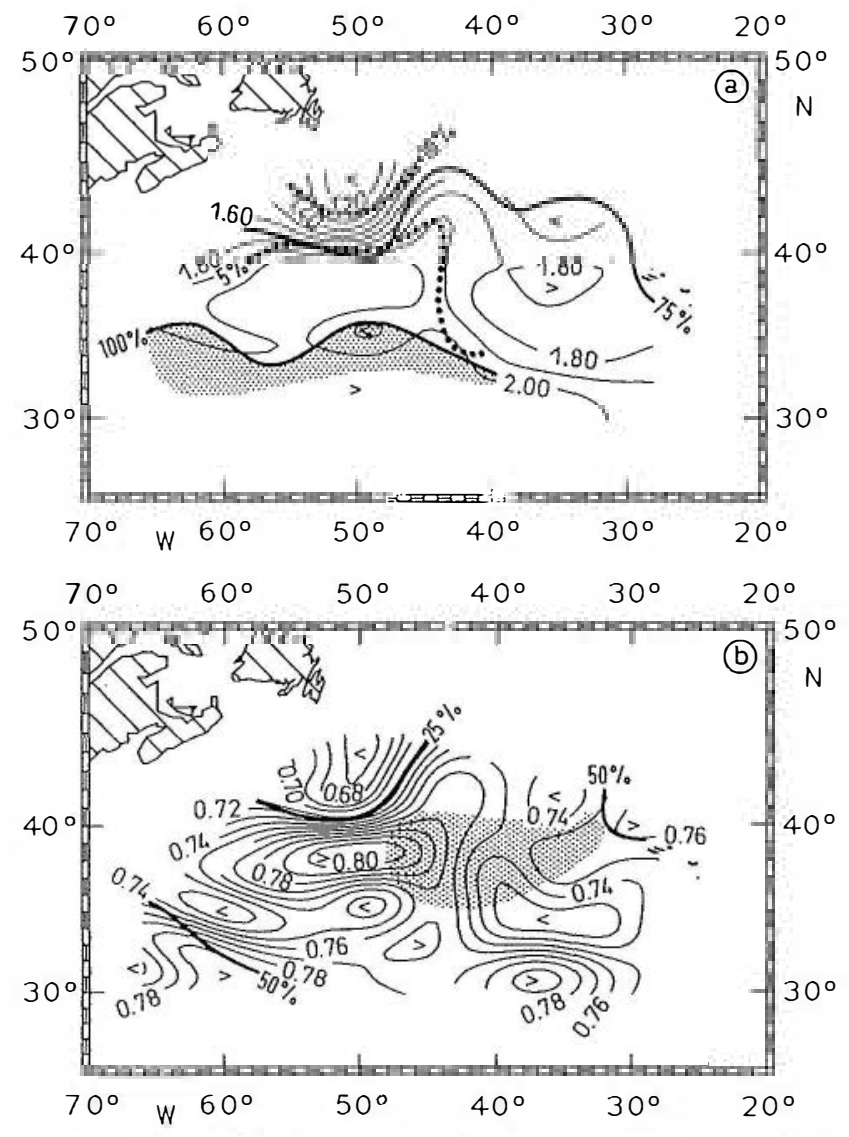

Fig. 4. Dynamic topography: (a) 50/2500 dbar, with WNACW (solid) and LCW (dotted) fraction lines for the 100-m level, and $(b)$ $1000 / 2500 \mathrm{dbar}$, with WNACW fraction lines (solid) for the $1000-\mathrm{m}$ level and the MW tongue (shaded).

area near $39^{\circ} \mathrm{N}$, marked by the $1.50-1.90$ dyn m contour lines, well correlated with the $75 \%$ line of WNACW and the $5 \%$ line of LCW. On its inshore side (1.20-1.40 dyn $\mathrm{m})$ the Gulf Stream is flanked by southward flowing LCW, SH, and WASIW. Near $50^{\circ} \mathrm{W}$ both the warm and the cold flank of the Gulf Stream turn northward, forming the NAC, which is characterized by lower dynamic contours. This agrees very well with the orientation of the water mass contours of again $75 \%$ WNACW and $10 \% \mathrm{LCW}$, the latter reflecting the axis of the cold flank. The AC originates near $41^{\circ} \mathrm{N}, 44^{\circ} \mathrm{W}$, where the 1.80-1.90 dyn m contour lines as well as the $5 \%$ line of LCW turn sharply southward. Farther north, the 75\% line of WNACW also deflects to the southeast. Moreover, the AC is accompanied by large amounts of $\mathrm{SH}$ in the main thermocline (not shown), which drastically change the water mass characteristics; Shelf Water is obviously present east of $36^{\circ} \mathrm{N}, 44^{\circ} \mathrm{W}$, where the AC turns southeastward, separating colder and fresher water masses originating in the north from the typical Sargasso Sea water.

The 1000-m level (Figure 4b) also resembles closely the main circulation pattern for the Gulf Stream and the NAC (25\% WNACW), but the circulation of the westward oriented MW tongue does not come out quite as unambiguously. Krauss et al. [1990] assumed a westward propagating tongue only south to the main axis of the AC. The meridional extent of the MW plume was found to be restricted by the $\mathrm{AC}$ in the south, and the southern branch of the NAC in the north [Sy, 1988]. 
TABLE 2a. Results From the Bermuda-Azores Section With Water Type Definition Changed by the Variance Due to Measurement Errors

\begin{tabular}{lrrrrrrr}
\hline \multicolumn{1}{c}{ Parameter } & $\begin{array}{c}\text { Upper } \\
\text { WNACW }\end{array}$ & $\begin{array}{c}\text { Lower } \\
\text { WNACW }\end{array}$ & AAIW & NADW & LCW & SH & MW \\
\hline Temperature, ${ }^{\circ} \mathrm{C}$ & 19.000 & 7.000 & 3.500 & 3.500 & -0.280 & 10.026 & 13.200 \\
Salinity & 36.670 & 34.980 & 34.530 & 34.925 & 33.350 & 34.989 & 37.740 \\
Oxygen, $\mathrm{mL} / \mathrm{L}$ & 5.500 & 3.850 & 3.900 & 6.150 & 8.150 & 5.720 & 4.500 \\
Nitrate, $\mu \mathrm{mol} / \mathrm{L}$ & 2.700 & 19.300 & 32.300 & 16.900 & 4.000 & 12.860 & 8.400 \\
Phosphate, $\mu \mathrm{mol} / \mathrm{L}$ & 0.200 & 1.250 & 2.250 & 1.150 & 0.550 & 0.930 & 0.660 \\
Silicate, $\mu \mathrm{mol} / \mathrm{L}$ & 2.500 & 14.500 & 45.500 & 11.500 & 4.800 & 6.080 & 5.500 \\
\hline
\end{tabular}

\section{ERror Estimation}

The consistency of water mass fractions in space, the fact that computed distributions agree well with known circulation features, and the continuity of features even for water masses present with very small fractions only, all indicate that the results reflect the physics of the region qualitatively well. In order to assess the quantitative validity of the results, we tested their sensitivity to variations in the source water matrix $G$ to errors of the model itself, namely, the assumption that all water types can be explained by mixing of fixed water types, and measurement errors of the initial data $d$. Table 2 gives the result of such a test corresponding to variation in the definition of water types for the BermudaAzores section. The western part of the section, reflecting the Sargasso Sea, is dominated by WNACW at the upper levels and by NADW at the lower levels, with small fractions of MW and AAIW at middepth. The eastern part is influenced by the Azores Current, transporting a large amount of LCW and SH toward the southeast. We changed the water type definition matrix by adding to or subtracting from its elements the variance due to measurement error resulting from instrument performance and analytical techniques. Table 2 demonstrates that the effect on the upper endpoint of the WNACW fraction is insignificant, whereas noticeable changes are observed for lower WNACW, NADW, and SH. In general, variations in the fractions of these water masses are on average in the range $1.5-2.5 \%$ if only errors due to measurement and analytical techniques are taken into account. Water masses with very low fractions, such as AAIW and $\mathrm{MW}$, show smaller variation. The same is true for the equation of mass conservation, which is only slightly altered by the changes to the water type definitions (not shown).

Histograms of residuals for all observation parameters are shown in Figure 5. The magnitude of most residuals exceeds the range that could be explained by measurement error and analytical techniques. The most plausible explanation for the observed range is that it is a result of environmental variability of water mass properties, i.e., an effect of seasonal and interannual changes in the source water types in re- sponse to changes of the atmospheric conditions in the formation regions. The relative magnitudes are comparable to those found in the Indian Ocean [You and Tomczak, 1992, 1993], i.e., $10 \%$ of the overall range of temperatures and salinities and up to $20 \%$ of the overall range of the other parameters. The standard deviations of all parameters are listed in Table 3. Their magnitude can be reduced by reducing the weight given to mass conservation.

In order to analyze uncertainties of the mixing ratios due to environmental variability of the model, all parameters of the initial data were perturbed by the most frequent deviations (Figure 5) between initial data and the results of the regression model. The results for the Bermuda-Azores section are shown in Table 4 . Water masses mainly dominating the upper levels (upper WNACW, LCW, and SH) were only slightly modified. Again, water masses that are mainly present in middepth and deeper layers are also more affected by the model's environmental variability (2-3\%). Remarkable changes occur for the AAIW, perhaps comparable to the estimates themselves. In comparison with AAIW, the modification of the fractions of MW is on average very small.

Of more interest in the context of regional oceanography is a measure of how the uncertainty in the description of the parameter fields translates into the determination of water mass contributions. The changes introduced in the water type definitions are comparable to those found in the parameter error fields, whereas the magnitude of most residuals caused by environmental variability exceeds the range of measurement errors. Tests performed for two single stations in the Gulf Stream region and the Sargasso Sea exhibit on average only small deviations $(0.7 \%)$ of the water mass fraction when the initial data were altered by their inherent measurement errors. The fact that water mass contributions vary little in response to these changes testifies for the robustness of the results.

Another measure for the quality of the results is the total residual for the mass conservation equation. A histogram for all 435 observation points (Figure $6 a$ ) indicates that at all stations mass is conserved to within $0.9 \%$; almost $98 \%$ of

TABLE 2b. Results From the Bermuda-Azores Section With Mean Deviations and Their Corresponding Standard Deviations Between the Results of the Water Type Definitions of Tables 1 and $2 a$

\begin{tabular}{lccccccr}
\hline & $\begin{array}{c}\text { Upper } \\
\text { WNACW }\end{array}$ & $\begin{array}{c}\text { Lower } \\
\text { WNACW }\end{array}$ & AAIW & NADW & LCW & SH & MW \\
\hline Number & 110 & 110 & 28 & 51 & 17 & 23 & 41 \\
Mean deviation, \% & 0.57 & 1.54 & 0.69 & 1.84 & 0.82 & 2.44 & 0.75 \\
Standard deviation & 0.59 & 1.35 & 0.76 & 1.01 & 0.70 & 2.22 & 0.47 \\
\hline
\end{tabular}



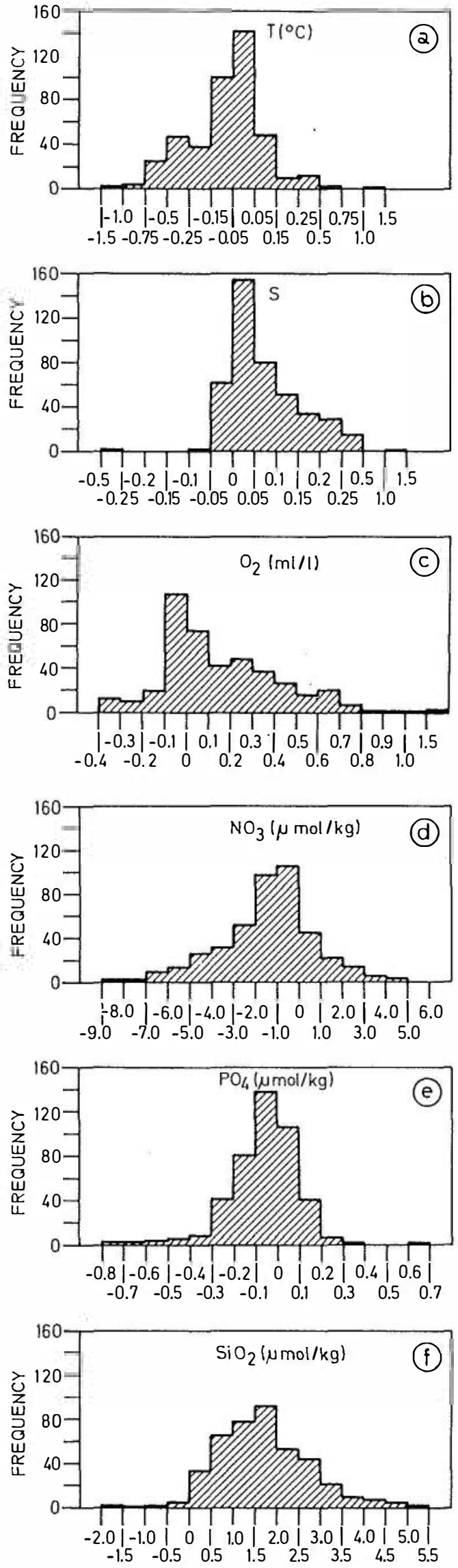

Fig. 5. Histograms of parameter residuals (difference between initial data and regression model): $(a)$ in situ temperature, $(b)$ salinity, $(c)$ oxygen, $(d)$ nitrate, $(e)$ phosphate, and $(f)$ silicate.
TABLE 3. Standard Deviations for Parameter Residuals (Differences Between Initial Data and Regression Model)

\begin{tabular}{lc}
\hline \multicolumn{1}{c}{ Parameter } & Standard Deviation \\
\hline Temperature, ${ }^{\circ} \mathrm{C}$ & 0.2413 \\
Salinity & 0.1775 \\
Oxygen, $\mathrm{mL} / \mathrm{L}$ & 0.2638 \\
Nitrate, $\mu \mathrm{mol} / \mathrm{L}$ & 2.0856 \\
Phosphate, $\mu \mathrm{mol} / \mathrm{L}$ & 0.1517 \\
Silicate, $\mu \mathrm{mol} / \mathrm{L}$ & 1.2080 \\
\hline
\end{tabular}

stations yield the correct value for the conservation of mass within $0.5 \%$. Figures $6 b$ through $6 f$ give the results of a subdivision of all available solutions into groups with different numbers of water masses used in the analysis. It is seen that the residuals decrease with increasing number of source water types. The largest residuals are found in cases where the solution consists of a single water mass, i.e., the station is located in the formation region of the water mass. Largest residuals for solutions yielding only a single water mass were mainly occupied in the $100-\mathrm{m}$ level, especially in the regions of $100 \%$ WNACW. Since nutrients at this level could not be defined as completely conservative owing to biological activities, larger residuals in the fractions of these water masses might also be related to variability in production and consumption of nutrients. This effect seems to be produced by variability of source properties in space and time and related to the nonnegativity constraint of OMP analysis, although the size of the residual depends on the number of degrees of freedom in the regression. The error can be made negligible compared with uncertainty in the solution caused by uncertainty in the initial data [Lawson and Hanson, 1974]. The OMP analysis can yield zero residuals exactly with the expense of increased uncertainty in the regressed parameter estimates, in the case that enough water masses are available.

Consider, for example, the source characteristics of AAIW, which is one of the freshest of the oceanic water masses. If AAIW during a particular year happens to be slightly fresher than average (which is the value used in the definition matrix), classical mixing analysis for a station in the source region would indicate an AAIW fraction $>100 \%$, balanced by a negative fraction of another water mass; it would also satisfy mass conservation exactly. OMP analysis enforces a positive solution for all water masses at the expense of mass conservation. This problem occurs only at the extreme ends of the parameter ranges (which by definition are the unmixed source water masses). Mixed water bodies always have characteristics with positive solutions for all fractions.

The analysis of error estimation yields different results for the expected three error sources. Deviations due to measurement errors are insignificantly small $(0.7 \%)$. In general, there is no effect on the small-fraction water types. Errors in the source water definition are on average not larger than $2.5 \%$. One has to take into account that the complete water type definitions were altered by the variance of the mostly observed WNACW, reflecting the strong influence of its seasonal and interannual variations due to different atmospheric conditions in their formation regions. These values of variances and the corresponding deviations seem to be too high for the other water types considered, e.g., AAIW and 
TABLE 4. Mean Deviations and the Corresponding Standard Deviations Between the Initial Data Set and Their Modification by Environmental Variability

\begin{tabular}{lcccccccc}
\hline & $\begin{array}{c}\text { Upper } \\
\text { WNACW }\end{array}$ & $\begin{array}{c}\text { Lower } \\
\text { WNACW }\end{array}$ & AAIW & NADW & LCW & SH & MW \\
\hline Number & 109 & 104 & 54 & 45 & 15 & 20 & 45 \\
Mean deviation, \% & 0.98 & 2.30 & 3.11 & 2.25 & 0.85 & 1.20 & 1.05 \\
Standard deviation & 0.82 & 2.01 & 1.64 & 0.79 & 1.03 & 1.24 & 0.42 \\
\hline
\end{tabular}

NADW, since seasonal and interannual changes in their formation regions are relatively smaller. Environmental variability yields the most important error source in OMP with errors amounting up to more than $3 \%$ for the most frequent deviations between the regression model and the initial data set. This error source has relatively small influence on the main contributors of water masses in the observation area,
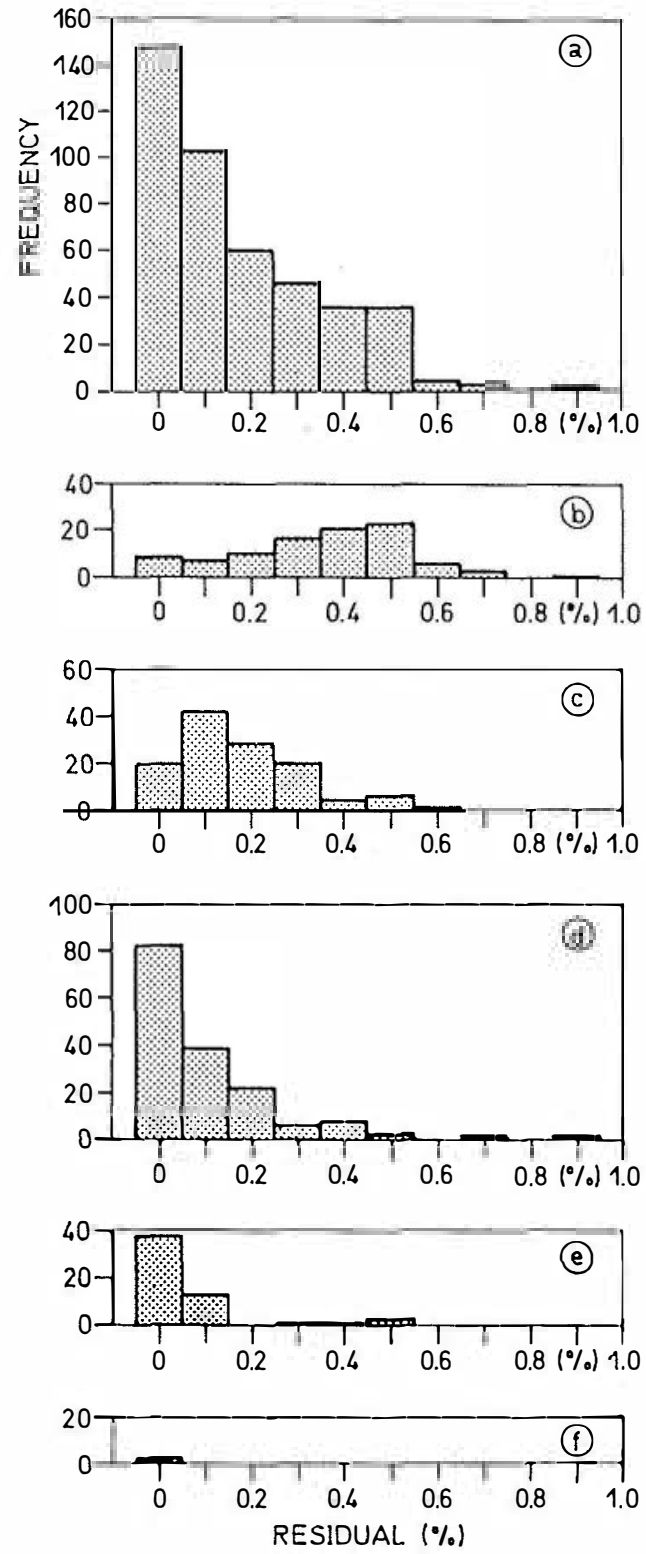

Fig. 6. Histograms of mass conservation residuals $(a)$ for all observation points, and using $(b)$ one, $(c)$ two, $(d)$ three, $(e)$ four, and $(f)$ five water masses for the analysis. but low fraction water types, such as AAIW, could become statistically insignificant for this analysis.

\section{Summary And Conclusions}

This paper reports on an application of optimum multiparameter analysis, an extension of classical temperaturesalinity analysis [Tomczak, 1981], to a complex situation involving a multitude of water masses. OMP analysis produces a quantitative description of water masses for the depth range of upper and intermediate waters $(100-1500 \mathrm{~m})$ in the western North Atlantic. Owing to the availability of six observation parameters the method is able to analyze mixtures of up to seven water types. It is shown that this is adequate to resolve the complexities of the water mass distribution in our observation area, especially on the continental slope of North America.

The study of the surveyed area reveals large contrasts in the water mass structure. Most of the upper waters in the southwestern part display subtropical conditions: a deep reaching main thermocline in the northern Sargasso Sea entirely covered by pure WNACW. In the Gulf Stream region the water mass distribution is characterized by a pool of warm, saline water on the offshore side and a change at the inshore flank as a result of enhanced horizontal mixing with waters originating in the Labrador Sea. Further downstream in the Gulf Stream extension area, the water mass structure becomes increasingly complex and ill defined, but the North Atlantic Current is seen transporting dense water of Labrador Current origin. As a consequence, the water masses east of the NAC are strongly influenced by LCW and $\mathrm{SH}$. The southeastward flowing Azores Current is seen in the southern section by the presence of large amounts of Labrador Current Water and Shelf Water; it clearly serves as a separation zone between water masses of northern origin and the pure WNACW in the Sargasso Sea.

Waters at intermediate depths are dominated by NADW; in the eastern part of the observation area they are influenced by the westward oriented tongue of Mediterranean Water. Occasionally, and particularly in the Gulf Stream region, the intermediate layers come into contact with AAIW. In contrast to MW and AAIW, which show oceanwide distributions, WASIW was observed in a small region only. It is present at the continental slope with amounts of up to $90 \%$ and can be traced along the inshore flank of the NAC but was not found anywhere else in our analysis.

The largest amounts of NADW were found at shallow depths toward the northwestern edge of the study area. This suggests that NADW originates in the vicinity of the Grand Banks. The same is found for Shelf Water and WASIW, which also show their largest relative contributions here.

Although OMP analysis by its very nature has to contend with the relatively sparse vertical resolution of bottle casts, 
the method is sensitive enough to show the effects of the eddy field and Gulf Stream rings on the water mass distribution, because eddies and Gulf Stream rings retain the signature of their original waters for long times and distances [Ring Group, 1981]. A cold core ring observed south of the main axis of the Gulf Stream can be identified as an isolated feature containing large amounts of $\mathrm{LCW}$ and $\mathrm{SH}$ in the upper water and a remarkably large contribution of NADW toward shallower depth. Comparisons in water mass distribution of two different cold core rings represent their actual stage of development [Ring Group, 1981], which also might give some information on their relative age.

Furthermore, the majority of the eddies are characterized by either a vertical displacement of NADW in deeper layers (Sargasso Sea) or the existence of water masses in the main thermocline such as LCW and $\mathrm{SH}$ which originate in the north (an example is the eddy located near the Azores). OMP analysis thus not only supports the pattern of the mean circulation in the western North Atlantic but can also give an indication of the eddy formation regions.

Maps of the water mass distribution show remarkable similarity to the dynamic height field. The position of the main axis of the Gulf Stream and the NAC is clearly seen in the water mass distribution. The Gulf Stream axis and the core of the NAC are near congruent with contours of WNACW and LCW content at the 100-m level. The Azores Current, which originates in the transition region between the Gulf Stream and the NAC [Klein and Siedler, 1989], is characterized by increased presence of Labrador Current and Shelf Water in the main thermocline; this has a major influence on the water mass distribution east of the Sargasso Sea.

Acknowledgments. This work was initiated while one of us (M.T.) was on sabbatical at the Institut für Meereskunde in Kiel. Use of facilities is gratefully acknowledged. We thank A. Schurbohm for carefully preparing the figures and especially J. Holtorff who developed the software for the color graphics. The work was supported by the Deutsche Forschungsgemeinschaft (SFB 133 "Warmwassersphäre des Atlantiks").

\section{REFERENCES}

Bainbridge, A. E., GEOSECS Atlantic Expedition, vol. 2, Sections and Profiles, National Science Foundation, Washington, D. C., 1976.

Cheney, R. E., and P. L. Richardson, Observed decay of a cyclonic Gulf Stream ring, Deep Sea Res., 23, 143-155, 1976.

Clarke, R. A., H. Hill, R. F. Reiniger, and B. A. Warren, Current system south and east of the Grand Banks of Newfoundland, $J$. Phys. Oceanogr., 10, 25-65, 1980.

Emery, W. J., and J. Meincke, Global water masses: Summary and review, Oceanol. Acta, 9, 383-391, 1986.

Fuglister, F. C., Cyclonic rings formed by the Gulf Stream, 1965-66, in Studies in Physical Oceanography: A Tribute to Georg Wïst on His 80th Birthday, edited by A. Gordon, pp. 137-168, Gordon \& Breach, New York, 1971.

Gould, W. J., Physical oceanography of the Azores front, Prog. Oceanogr., 14, 167-190, 1985.
Käse, R. H., and G. Siedler, Meandering of the subtropical front southeast of the Azores, Nature, 300(5889), 245-246, 1982.

Käse, R. H., W. Zenk, T. B. Sanford, and W. Hiller, Currents, fronts and eddy fluxes in the Canary Basin, Prog. Oceanogr., 14, $231-257,1985$

Kawase, M., and J. L. Sarmiento, Nutrients in the Atlantic thermocline, J. Geophys. Res., 90, 8961-8979, 1985.

Klein, B., and G. Siedler, On the origin of the Azores Current, $J$. Geophys. Res., 94, 6159-6168, 1989.

Krauss, W., R. H. Käse, and H.-H. Hinrichsen, The branching of the Gulf Stream southeast of the Grand Banks, J. Geophys. Res., 95, 13,089-13,103, 1990.

Lawson, C. L., and R. J. Hanson, Solving Least Squares Problems, 180 pp., Prentice-Hall, Englewood Cliffs, N. J., 1974.

Mann, C. R., A. R. Coote, and D. M. Garner, The meridional distribution of silicate in the western Atlantic Ocean, Deep Sea Res., 20, 791-801, 1973.

McLellan, H. J., On the distinctness and origin of the slope off the Scotian shelf and its easterly flow south of the Grand Banks, $J$. Fish. Res. Bd. Can., 14, 213-239, 1957.

Metcalf, W. G., Dissolved silicate in the deep North Atlantic, Deep Sea Res., 16, 139-145, 1969.

Rhein, M., and H.-H. Hinrichsen, Modification of Mediterranean Water in the Gulf of Cadiz, studied with hydrographic, nutrient and chlorofluoromethane data, Deep Sea Res., 40, 267-291, 1993.

Ring Group, Gulf Stream cold-core rings: Their physics, chemistry, and biology, Science, 212, 1091-1100, 1981 .

Soule, F. M., Physical oceanography of the Grand Banks region, Labrador Sea and Davies Strait in 1938, Bull. U.S. Coast Guard, 28, 113-173, 1951.

Sy, A., Investigation of the large scale circulation patterns in the central North Atlantic: The North Atlantic Current, the Azores Current, and the Mediterranean Water plume in the area of the Mid-Atlantic Ridge. Deep Sea Res., 35, 383-413, 1988.

Tomczak, M., A multiparameter extension of temperature/salinity diagram techniques for the analysis of non-isopycnal mixing, Prog. Oceanogr., 10, 147-171, 1981.

Tomczak, M., and D. G. Large, Optimum multiparameter analysis of mixing in the thermocline of the eastern Indian Ocean, $J$. Geophys. Res., 94, 16,141-16,149, 1989.

Worthington, L. V., On the North Atlantic circulation, Johns Hopkins Univ. Stud. Oceanogr., 6, 110 pp., 1976.

Wright, W. R., and L. V. Worthington, The water masses of the North Atlantic Ocean: A volumetric census of temperature and salinity, in Serial Atlas of the Marine Environment, folio 19, 8 pp., 7 plates, Am. Geogr. Soc., New York, 1970.

Wüst, G., and A. Defant, Atlas zur Schichtung und Zirkulation des Atlantischen Ozeans, Schnitte und Karten von Temperatur, Salzgehalt und Dichte, Wiss. Ergeb. Dtsch. Atl. Exped. Vermessungs. Forschungsschiff Meteor 1925-1927, 6, 103 plates, 1936.

You, Y., and M. Tomczak, Analysis of the large scale water mass structure in the thermocline of the Indian Ocean by singular value decomposition, Flinders Inst. for Atmos. and Mar. Sci., Res. Rep. 54, Flinders Univ., Adelaide, S. Australia, 1992.

You, Y., and M. Tomczak, Thermocline circulation and ventilation in the Indian Ocean derived from water mass analysis, Prog. Oceanogr., in press, 1993.

H.-H. Hinrichsen, Institut für Meereskunde an der Universität Kiel, Diisternbrooker Weg 20, D-2300 Kiel 1, Germany.

M. Tomczak, Flinders Institute for Atmospheric and Marine Sciences, Flinders University, GPO Box 2000, Adelaide, S. A. 5001, Australia.

(Received February 20, 1992;

revised December 7, 1992;

accepted December 15, 1992.) 